\title{
A foundation for presentism
}

\author{
Robert E. Pezet ${ }^{1}$
}

Received: 15 April 2015 / Accepted: 16 January 2016 / Published online: 3 February 2016 (c) The Author(s) 2016. This article is published with open access at Springerlink.com

\begin{abstract}
Presentism states that everything is present. Crucial to our understanding of this thesis is how we interpret the 'is'. Recently, several philosophers have claimed that on any interpretation presentism comes out as either trivially true or manifestly false. Yet, presentism is meant to be a substantive and interesting thesis. I outline in detail the nature of the problem and the standard interpretative options. After unfavourably assessing several popular responses in the literature, I offer an alternative interpretation that provides the desired result. This interpretation is then used to clarify the distinction between 'real change' from mere variation and temporal relativisation. Reflecting on my solution, I try to diagnose the source of confusion over these issues. Then, building upon Fine's (Modality and tense, 2005) distinction between ontic and factive presentism, I elucidate what the presentist thesis specifically concerns and how best to formalise it. In the process I distinguish a weak and strong (extended) version of the presentist thesis. Finally, I end by drawing out some limitations of the paper.
\end{abstract}

Keywords Change · Ontological Realism · Presentism · Tense · Triviality

Presentism is the metaphysical thesis that 'all and only present things exist'. Let us call this the 'presentist thesis'. What this amounts to depends on the way we interpret the concepts employed in the statement of that thesis. For our purposes, a 'theory' shall be a way of understanding a 'thesis'. That is, a thesis provides the skeletal structure to a theory; a broad declarative claim on a subject matter. A theory then "fleshes out" out that claim by providing an elaborative interpretation of that skeletal structure which serves to precisify the thesis and specify what it amounts to. Of central importance to

Robert E. Pezet

js06rep@leeds.ac.uk

1 Philosophy PhD Student, University of Leeds, Leeds LS2 9JT, UK 
our understanding the presentist thesis is how we interpret 'present' and 'exist'. In this paper, we shall explore the notion of existence and its relation to presentness, and by so doing, gain a better grasp of what an interesting presentist theory might look like.

Some have thought that the relationship between the concepts of existence and presentness is too intimate for presentism to be the substantive and interesting thesis it ought to be. Despite initial appearances, I think that this triviality charge against the presentist thesis is mistaken. My primary focus will be on elaborating and refuting this charge (Sects. 1 and 2 respectively). This will require the deliverance of an account of existence that does not analytically settle the presentness of existents. We will need to be cautious that this account does not prejudge or bias our assessment of presentism, and we ought ultimately to offer a diagnosis and treatment of the source confusion that ultimately inspired the charge.

My solution to the triviality charge will then be employed to distinguish between dynamic and static ways of construing change (Sect. 3). This distinction is crucial to our being able to capture what is meant by temporal passage, which perhaps provides the most compelling common sense inclination towards the non-philosopher's presentist skew. That is, many have complained that the static conception of time-the view that treats time like space, without metaphysically privileged positions-does not account for any 'real change'. And, of course, our complainant will often take such real change as manifestly evident in their experience. However, perhaps paradoxically, they have often struggled to distinguish 'real change' from less controversial kinds of change that even static accounts of time can accept. In particular, I will distinguish metaphysical change (dynamic change) from mere temporal variation and temporal relativisation (static forms of change). These distinctions between dynamic and static ways of construing change will allow us to express what is at stake in this debate.

I will then attempt to diagnose the underlying source from which the triviality objection draws its strength (Sect. 4). It is claimed that the objection presupposes a biased conception of the priority between time and existence. And that given this biased conception, it is no wonder that presentism turns out as a trivial thesis. However, this begs the question against Eternalism, the thesis that all past, present, and future things are equally real. Eternalists take an alternative stance on the priority between time and existence, and it is because this stance is eliminated from consideration from the start that presentists are not able to make their substantive claim.

Finally, I will clarify the presentist thesis by emphasising what it is and is not about (Sect. 5). In particular, I draw on Fine's (2005b) distinction between ontic and factive presentism to stress that the presentist thesis concerns ontology rather than the nature of facts. This is then related to the distinction between de re and de dicto claims and to draw out a limitation and potentially desired extension to the presentist thesis. In what follows, I will follow Arthur Prior in using tense operators to representing claims about the A-determinations, pastness, presentness, and futurity. By employing tense operators to express the A-determinations, I mean that we will represent pastness, presentness, and futurity by the operators 'It was the case that...', 'It is (now) the case that...', and 'It will be the case that...' respectively. Symbolically, we may express the past tense operator by ' $\mathbf{P}(\ldots)$ ', the present tense operator by ' $\mathbf{N}(\ldots)$ ', and the future tense operator by ' $\mathbf{F}(\ldots)$ '. These operators may take any proposition as an argument and form a new one. It is also permissible that the operators appear within the scope of 
quantifier and take ascriptions concerning bounded entities as their argument to form new ascriptions concerning those bounded entities. Ultimately, this paper will set the foundations necessary for a sensible dialectic over the presentist thesis made possible by permitting us crucial distinctions that we otherwise could not make.

\section{The triviality objection}

Unsurprisingly, there has been a recent surge in the literature claiming that presentism is either trivially true or obviously false (cf. Dorato 2006; Lombard 1999, 2010; Meyer 2005, 2013; Savitt 2006). The controversy is best described as concerning the status of the 'is' in standard characterisations of presentism, such as:

Standard: 'Everything is present'.

The problem is that we can interpret the 'is' in various ways, but according to the objectors, none of the interpretations are of any use to the presentist. Many philosophers throughout history have lamented the ambiguity of the copula. Consider for example the following four interpretations of 'is' familiar from the works of Frege and Russell:

I. Existential: This asserts that a thing exists. For example, 'Socrates $i s$ '. Rendered as ' $\exists x$ ( $x=$ Socrates $)$ '.

II. Identity: This asserts the identity relation between things. For example, 'Bruce Wayne is Batman'. Rendered as 'Bruce Wayne = Batman' .

III. Predication: This asserts the instantiation of a property by something. For example, 'Socrates is wise'. Rendered as 'Wise(Socrates)'.

IV. Generic Implication (Inclusion): This asserts that one class of things belongs to (is a subset of) another. For example, 'A triceratops is an herbivore'. Rendered as ' $\forall x$ (Triceratops $(x) \rightarrow$ Herbivore $(x))$ '.

But across these four disambiguations of 'is' there appears to be an orthogonal further level of ambiguity residing in our interpretation. This further dimension of ambiguity concerns the tense of the 'is', or lack of it. A helpful disambiguation of 'is' along the temporal axis has been offered by Rescher (1966), and serves as the platform for Savitt's (2006) version of the triviality objection:

The temporal equivocation of 'is' has, however, been little heeded. Yet it is quite clear that there are several very distinct possibilities:

(i) The "atemporal is" that means "is timelessly." ("Three is a prime number.")

(ii) The "is of the present" that means "is now." ("The sun is setting.")

(iii) The "omnitemporal is" that means "is always." ("Copper is a conductor of electricity.")

(iv) The "transtemporal is" that means "is in the present period." ("The earth is a planet of the sun.")

\footnotetext{
${ }^{1}$ How tense interacts with this sense of 'is' is key to the debate between occasional and permanent identity (cf. Gallois 1998).
} 
In contrast to the atemporal 'is' of (i), the uses of 'is' at issue in (ii)-(iv) may all be characterized as temporal. (Rescher 1966, pp. 75-76)

Given interpretation (ii), Standard would read as 'Everything is (now) present'. On this interpretation, the occurrence of 'present' seemingly acts as no more than a mere pleonasm. It is not surprising then that this has attracted the charge of triviality. The objector explains, of course if we restrict ourselves to what exists now, then everything is present. But if this is what presentism amounts to, no one should reject it. Presentism is meant to be a substantive thesis, yet interpretation (ii) makes its truth analytic. However, interpretations (iii) and (iv) appear to do little better. Under interpretation (iii), Standard would read as 'Everything is (always) present'. Though this interpretation is not obviously incoherent, any variety of presentism that emerges from it, our objector contends, is obviously false. Some things are not always present; there is change over time in what things exist. Whilst interpretation (iv), wherein Standard reads as 'Everything is (in the present period) present', will either be trivial, if the period is wholly present, or obviously false, if the period exceeds the present's extent.

That exhausts Rescher's temporal interpretations of 'is', but what about the atemporal interpretation? On a narrow construal of interpretation (i), Standard reads as 'Everything is (timelessly) present'. Prima facie, the interpretation just seems illformed. Take, for example, the sentence, 'The firing of the gun is (timelessly) an event which will take place tomorrow'. Prior was left dumbfounded by what sense can be made of this sentence: 'What place can a word like 'tomorrow' have in a strictly tenseless form?' (1957, p. 106). Likewise, one might wonder what sense 'present' has when combined with the atemporal or tenseless interpretation of 'is' in Standard. I am sympathetic to Prior's bewilderment, but Savitt has offered one plausible broad interpretation of how to understand the tenseless copula so that it applies to temporal entities. His suggestion is captured in the passage below wherein the boldfaced verbs are tenseless:

Suppose, then, that tenseless verbs apply to temporal as well as non-temporal entities. One might admit as meaningful or truth-valued sentences like 'Socrates SITS at t' or possibly even just 'Socrates SITS', along with sentences like 'Three IS greater than two'. But how is one to understand these sentences? One suggestion I find useful is that we think of the tenseless verbs in such sentences as like ordinary tensed verbs but lacking all temporal information (just as ordinary verbs lack spatial information), while compatible or consistent with the addition of temporal information. On this understanding of tenseless verbs, the claims 'Isaac Newton EXISTS in 1666' and 'Isaac Newton EXISTS' are well-formed. (2006, p. 114)

The thought seems to be that, if there was a time when something was, is (now), or will be, then it 'is' in this tenseless sense of 'is', since the 'is' is meant to be irrespective of temporal location. But unlike the detensed or omnitemporal sense of 'is' (interpretation (iii)), this interpretation would be applicable to atemporal, as well as temporal, content. This broad construal of interpretation (i) at least yields a wellformed result for Standard, yet does no better than the detensed sense of 'is', where for analogous reasons, this interpretation of Standard appears manifestly false. If 
this is the story, and Savitt concurs, the tenseless 'is', in either of its narrow or broad senses, is not any help to presentists. So none of Rescher's disambiguations of 'is' along the temporal axis is of any help to the presentist. Or at least this is what the objector contends.

We can formulate the resulting objection to presentism accordingly:

A1. Standard is both substantive and not manifestly false. (Presentist Thesis) P1. The 'is' in Standard must have one, and only one, of Rescher's four interpretations: (i), (ii), (iii), or (iv). (Interpretative Exhaustion) P2. If the 'is' in Standard is interpreted with Rescher's (i), then Standard is manifestly false.

(Atemporal)

P3. If the 'is' in Standard is interpreted with Rescher's (ii), then Standard is trivial (not substantive).

(Temporal)

P4. If the 'is' in Standard is interpreted with Rescher's (iii), then Standard is manifestly false.

(Omnitemporal)

P5. If the 'is' in Standard is interpreted with Rescher's (iv), then Standard is either manifestly false or trivial (not substantive).

(Transtemporal)

C1. It is not the case that A1.

(Presentist Antithesis)

By the 'triviality objection', from now on, I shall mean this argument. The argument is a clearly valid reductio ad absurdum, and the above reasoning seems to present an airtight case for its soundness. But things are not always as they seem.

\section{Responses}

We will look first at a couple of popular responses to this argument before I offer my own explanation of where the argument fails. Seeing what is right and wrong about these responses was influential in forming my own response. I hope to separate these positives and negatives to persuade readers why my response is the correct way of answering the challenge.

\subsection{Existence simpliciter}

Perhaps the most popular response to the triviality objection takes a leaf out of a modal realist's book. There is an analogous triviality challenge to presentism's modal analogue, viz. Actualism. We can formulate a standard version of this position accordingly:

Standard Actualism: Everything is actual.

The worry is that we can either read the 'is' narrowly as meaning 'is (actually)', or broadly as meaning 'is (possibly)'. If we adopt the former interpretation, then Standard Actualism appears trivial; whilst if we adopt the latter interpretation, then Standard Actualism appears manifestly false.

The enormously influential philosopher David Lewis responded to the challenge by appealing to his conception of what there is simpliciter: 
When we quantify over less than all there is, we leave out things that (unrestrictedly speaking) exist simpliciter. If I am right, other-worldly things exist simpliciter, though often it is very sensible to ignore them and quantify restrictedly over our worldmates. And if I am wrong, other-worldly things fail simpliciter to exist. They exist, as the Russell set does, only according to a false theory. That is not to exist in some inferior manner-what exists only according to some false theory just does not exist at all. (1986, p. 3)

This notion of what there is simpliciter is meant to be neutral between the narrow and broad readings of the 'is' in Standard Actualism. Either possibilia exist in this neutral sense, or they do not, but neither disjunct is trivial or manifestly false. Those impressed by this response to the actualist triviality challenge have sought to give an analogous reply to the triviality objection against presentism. So, for example, Hestevold and Carter give us the following explication of existence simpliciter:

Existence Simpliciter: ' $X$ exists simpliciter, if and only if, $X$ is among the things that the universe includes - if and only if $X$ is real. That $X$ exists simpliciter does not alone imply that $X$ did exist, that $X$ presently exists, nor that $X$ will exist.' (2002, p. 499)

Employing this conception of what there is simpliciter in Standard will then give us:

Standard Simpliciter: Everything is (simpliciter) present.

How does this help us refute the triviality objection? The thought seems to be that Existence Simpliciter offers us another interpretative option that was overlooked. That is, this response rejects P1, that interpretations (i)-(iv) are exhaustive of the ways we can understand the 'is' in Standard.

But it should be clear that, if this is the response, it is not going to satisfy our objector. To see why this is, consider the following analogous remarks made by Tim Button to explain his crucial ' $x$ is real-as-of $y$ ' relation: 'The 'is' in ' $x$ is real-as-of $y$ ' is neither tensed nor tenseless. The relation ' $x$ is real-as-of $y$ ' is a primitive of nofuturism, and the verb it includes is just a part of that primitive.' (2007, p. 331). Can we really make any sense of his claim that the 'is' is neither tensed or tenseless? Tenseless just means without tense. So if a statement is not tensed, it must be tenseless. There simply is no third category! As Tallant explains, '...for Button to say that there is this third grammatical category that is lacking in tense, but not tenseless appears to be to commit to a contradiction.' (2011, p. 40). But, as Tallant immediately acknowledges, this is unduly harsh on Button, since his use of 'tenseless' in fact corresponds to the omnitemporal (interpretation (iii)) rather than atemporal (interpretation (i)) sense of 'is' (cf. Button 2006, pp. 131-132). And that the 'is' in his 'is real-as-of' relation is indeed the atemporal 'is'. ${ }^{2}$ Still, Tallant (Ibid., Sect. 3) continues by stressing that,

\footnotetext{
2 Thanks to an anonymous reviewer for this journal for pressing me on this point, and to Tim Button for providing a helpful clarification in personal correspondence. However, I still have my worries about treating the 'is' here in the atemporal sense, in accordance with Tooley's (1997) use of 'is' in his 'is as of a time'. Button explicitly rejects this atemporal perspective (cf. 2007, p. 327; see my comments in Sect. 3.2), so appeal to it here would seem illegitimate. I understand that this was the source of Button (2007, Sect. 5) own uneasiness about his 'is real-as-of' relation.
} 
if not strictly contradictory, the adding of a new grammatical category is not only hard to get a grip on, but also unprecedented. And so we should expect others to complain when it is suggested that there is an interpretation of 'is' that is not one of interpretations (i)-(iv).

If this is the right way to read the response, then it feels like a cheat. It offers an interpretation that is not meant to be any of (i)-(iv), yet does not explain how that interpretation can fail to be (i)-(iv). All we are really told is that it is a problem-free interpretation, and we are expected to take it for granted. This is essentially the riposte that Ulrich Meyer gives to reinforce his version of the objection:

No matter how we spell out the details of the proposal, an appeal to existence simpliciter does not expand the range of options. The only available disambiguations of the presentist thesis are the trivially true [interpretation (ii)] and the obviously false [interpretation (iii)], plus perhaps some intermediate positions [i.e. interpretations (i) and (iv)] that provide different combinations of the unappealing features of [interpretation (ii)] and [interpretation (iii)]. (This could happen if our notion of existence simpliciter is more restrictive than temporal existence, but also more permissive than present existence.) (2013, p. 69)

Yet perhaps this is not the right way to understand the response, for some, if not all, that give it. Theodore Sider is one of the most outspoken and clear proponents of the existence simpliciter response. He presses the point accordingly:

The world has distinguished 'logical joints': candidate meanings for logical words that are special, just as distinguished groupings (for instance the electrons) are special. The language of an ideal inquirer must contain logical words for these logical joints, just as it must contain predicates for the more commonly recognized natural kinds. One of the distinguished logical joints is a distinguished meaning, call it existence, for the existential quantifier.

[...] we can argue directly that the dispute between presentists and eternalists is genuine. Since the eternalist and the presentist both mean existence by their existential quantifiers, they mean the same thing by their existential quantifiers... (2006, pp. 81-82)

Eternalism is the anti-presentist thesis that all past, present and future things exist. This passage gives the impression that the intended objection, at least by Sider, is not meant to be against P1, since no new interpretation of 'is' is being offered. Rather, which of interpretations (i)-(iv) is in fact employed in Standard is not settled by us, but by the world. One of interpretations (i)-(iv) picks out a logical joint, and all participants in the temporal metaphysics debate intend to pick out that joint when discussing what there is.

That is, this response to the triviality objection simply bites the bullet. It is freely admitted that if Standard is true, then it is not a substantive thesis, it is trivial. Nevertheless, that Standard expresses a trivial truth, this respondent contends, is anything but trivial. It is from this further issue, whether nature's logical joints are best captured by interpretation (ii), that presentism gets its substance.

How then does this way of understanding the existence simpliciter response fare? Well, firstly, it assumes that there is a logical joint of nature that one or the other of the interpretations best carves out. This is far from obvious. Sider does suggest that there 
are some claims that can truly be made with the use of one interpretation of existence simpliciter (interpretation (i)) for which no true translation with another interpretation (interpretation (ii)) can be found. But he has to admit that it '...is not a conclusive refutation of the sceptic. The arguments just given that the presentist translations are false are metaphysically controversial; they turn on the difficult issue of whether a presentist ought to be a 'serious' presentist.' (Ibid., p.83). ${ }^{3}$ And what Sider needs to show is, not merely that nature has a logical joint for existence, but, that that joint is better captured with one of interpretations (i)-(iv) than the others. Even a realist about logical natural kinds can be sceptical about this.

Let us concede this point to Sider, for now, to combat another worrisome issue plaguing this proposal. For suppose that we were to discover, somehow, that nature's logical joints were tenseless. This would render Standard Simpliciter as equivalent to:

\section{Standard Tenseless: Everything is (atemporally) present.}

That is, the world renders the 'is' in Standard with interpretation (i). As we have seen, this interpretation renders presentism as manifestly (at least once any referential opacity is removed) false. Yet, surely, the presentist has the right to complain that the thesis stated in Standard Tenseless is not their thesis. After all, why believe something that is manifestly false? Once the referential opacity is removed, it becomes evident that presentists and non-presentists cannot have meant the same thing by the quantifiers. One of either presentists or non-presentists will have their conception of reality warped by nature's joints into an absurdity. Or, more precisely, the response contends that the statement of what the presentist thesis amounts to depends upon the world, nature's logical joints, and not (entirely) on us. Yet, this seems wrong. We develop theses in order to represent ways the world might be, independently of how the world in fact is. The representation needs to be transparent to us if it is to be any help in guiding our decisions. ${ }^{4}$

There are some exceptions to this representational transparency, however, that may have made the response tempting..$^{5}$ These exceptions come in two forms:

\footnotetext{
3 'Frivolous presentism' is the name given to a presentist theory that permits the possession of properties by a thing at times at which it does not exist. 'Serious presentism' denies this. For more on this distinction, see Bergmann (1999) and Hinchliff (1988, 2010). It seems to me that the issue of whether transtemporal relations, such as the admires relation, could be given a tense quantifier translation even without assuming 'serious presentism'. Sider is assuming that the expressed transtemporal relations correspond to real relations between particulars. Similarly for his set with transtemporal members. This is not problematic if fundamentally there are no such sets.

4 An anonymous referee suggests an interesting counterexample to this. Might the dispute over complex, plausibly analytic truths, such as Goldbach's conjecture - that all integers greater than two are the sum of two primes-be characterised as one where nature's logical joints determines the meaning of our terms, and disputants merely disagree over the meaning of their terms? I think that this mischaracterises the situation. Both parties agree over the meaning of the terms involved. Instead, it is due to the complexity of drawing out the implications of the meaning of those terms in proofs - and it is not obvious that there are worldly correlates or joints here-that the disagreement arises. Note also that there is no analogy here with the debate over our interpretation of the quantifiers, where the cognitive demands are significantly less great.

5 Most notably, these exceptions would be a quite frequent occurrence if mental content externalism is true. However, even where mental content externalism is true, it should be desirable to overcome, as best as we can, the externalist aspect of that content, by improving its internal transparency (its cognitive significance), when that aspect is relevant to our theorising.
} 
Irrelevant: When the opaque (world-dependent) aspect of the representation is irrelevant to our interest in the thesis, such that, how the world is in this respect does not affect the truth of the thesis.

Relevant: When the opaque (world-dependent) aspect of the representation is relevant to our interest in the thesis, such that, how the world is in this respect does affect the truth of the thesis.

Clearly, in the case of Irrelevant, representational transparency is not required, because how the world determines the opaque aspect of the representation does not matter to the truth of the thesis. When that aspect of the representation does matter with respect to the truth of the thesis, as in Relevant, then the thesis is only helpful if there is some (implicit or explicit) supposition, or disjunct of suppositions, about how the world is in the relevant respect. The thesis that we intend is then represented conditionally upon these suppositions being correct, and is not represented otherwise. That is, if we were to believe a thesis with relevant world-dependent representational aspects, we would do so conditionally upon our representational suppositions with respect to the world being correct. And this must be so on pain of the absurdity that we do not know what it is that we are consciously opinionated about. But, contrary Sider, astute presentists and non-presentist do know what they are consciously opinionated about, regardless of how the world in fact is. ${ }^{6}$

Still, might we not maintain, contra Sider, that presentists and non-presentists do mean different things by their quantifiers, where the 'is' in the quantificational 'there is' corresponds to either one of interpretations (i)-(iv)? Yet, like Sider, contend that the substance of the debate turns on, which of those interpretations carves at nature's logical joints, which exists simpliciter. This appears to be what Trenton Merricks was proposing in the following passage: 'I think presentists should, instead, say thatexisting at the present time just isexisting. Thus, given presentism, if something exists, then, obviously enough, it exists at the present time. So, given presentism, since everything exists, everything exists at the present time. This is what is right about the standard definitions of presentism.' (2007, p. 125). Despite their varied use of quantificational expressions, what stops presentists and non-presentists talking past one another is which of interpretations (i)-(iv) captures the 'is simpliciter' in Standard Simpliciter. That is, presentists will accept, whilst non-presentists will deny, that interpretation (ii) pick out some privileged logical joint in nature.

If we can make sense of logical joints, then this might indeed be a substantive dispute of sorts. However, it is unclear to me what this privilege amounts to. Moreover, I fear that it is not that which has primarily been in contention between presentists and non-presentists. After all, why could an eternalist, tensed realist, not accept that interpretation (ii) is privileged? Unlike the serious presentist, such an eternalist might reasonably be permitted the possession of properties by things at times which they do not exist. Crucially, those equating 'is simpliciter' with 'existing at the present

\footnotetext{
6 Note that the complaint here is not that a debate cannot be carried out in the way that Sider suggests. Rather, the complaint is that this in fact is not how we usually do and should conduct the kind of debate that Sider wants. Instead, those wanting to engage in this debate should do so in the upfront and transparent way that Merricks does below.
} 
time', as Merricks proffers, when making claims about what exists simpliciter would not thereby be making any interesting claims about the status of other times or their occupants, except perhaps the trivial claim that they do not exist at the present time. Yet, to make the substantive claims they want to make, presentists will need a notion of existence that is not restricted in this way. Giving trivialities certain privileges does not lessen their benality; it merely elevates them in some privileging way.

The positive point to take away from this response is that there must be an alternative interpretation from how we have so far understood (i)-(iv), if we are to make progress on this issue. And since interpretations (i)-(iv) seem to be undeniably exhaustive, the only option left is that there is an alternative way of understanding at least one of interpretations (i)-(iv). Moreover, that alternative way of understanding at least one of interpretations (i)-(iv) ought to, ideally, be neutral between presentists and non-presentists. This would allow for the common ground of dispute, the logical joint corresponding to the 'is' in Standard, that Sider informs us that both parties in this debate presume there to be.

\subsection{Tenseless existence}

An alternative response to our objector has been provided by Crisp (2003, 2004a, b). Crisp attempts to defend a detensed interpretation [interpretation (iii)] of Standard:

Standard Detensed: Everything was, is (now), or will be present.

And takes Standard Detensed to be equivalent to the statement 'For every $x, x$ is present', wherein the quantifier domain is unrestricted, or restricted to the domain of all temporal things, ' $\mathrm{D}_{\mathrm{t}}$ ' (i.e. things that existed, exist (now), or will exist). He recognises the objector's response to the detensed interpretation of Standard as claiming that it '... is trivially false and points to the Roman Empire as an obvious counter-example.' (2004a, p. 18). But Crisp then makes a crucial distinction between de dicto and de re intensional statements.

A de dicto intensional statement gives an intensional operator, such as one of our tense operators, a wide scope with respect to the quantifier. So, for example, the assertion:

A. It was the case that (for some $x, x$ is the Roman Empire),

formally translated as ' $\mathrm{P} \exists \mathrm{x}(\mathrm{Rx})$ ', is de dicto because the past tense operator precedes the quantifier in the expression such that it contains the quantifier in its scope. The de dicto intensional statement is about a proposition, which roughly corresponds to its translation from Latin as 'about what is said'. A de re intensional statement, on the other hand, gives an intensional operator a narrow scope with respect to the quantifier. So, for example, the assertion:

B. For some $x$, it was the case that ( $x$ is the Roman Empire),

formally translated as ' $\exists \mathrm{x} \mathbf{P}(\mathrm{Rx})$ ', is de re because the past tense operator succeeds the quantifier in the expression such that it is contained within the scope of the quantifier. The de re intensional statement is about a thing, which corresponds to its translation from Latin as 'about the thing'. 
Crisp happily concedes the manifest truth of such de dicto assertions, such as A, concerning the past or future, given Standard Detensed. But he claims that presentists need not be troubled by this concession. Presentists need only deny the truth of de re assertions, such as B, about some non-present particulars. Yet, Crisp maintains that there is nothing manifestly obvious about these de re assertions. This is the pivotal point, and is captured in the following passage:

It's certainly no Moorean fact that the domain of temporal things is still populated with something non-present and identical with the Roman Empire. Were it a Moorean fact that eternalism - the view that our most inclusive domain of quantification includes past, present, and future entities-is true, I suppose it would be a Moorean fact that $\mathrm{D}_{\mathrm{t}}$ includes the Roman Empire. But it's not just obvious that eternalism is true: it's not just obvious that our widest domain of quantification still includes wholly past objects like the Roman Empire. If eternalism is true, we need serious argument to see that it is. (Ibid., pp.18-19)

This response to the triviality objection falls neatly in line with Arthur Prior's view that the facts of what is no longer, or yet to be, are not about anything in particular, they are 'general facts'. So long as the quantification occurs within a modality operator, there is no existential entailment, '...that $F \exists x \varphi x \supset \exists x F \varphi x$ is not a law.' (Prior 1968, p. 221) and likewise for the past tense operator. ${ }^{7}$ In particular, the response rejects $\mathbf{P 4}$ of the triviality objection by denying that Standard Detensed is manifestly false.

This type of response against the triviality objection has, however, been condemned as ineffective by Meyer (2005). Meyer complains that this merely restricts the validity of existential generalisation-the inference from the fact that a particular $x$ is $\mathrm{F}$ to something (in general) being F-to names whose referent is present, and that this is just to slip back into a tensed interpretation of the existential 'is'. We see this especially in the first sentence of the quoted passage where Crisp wrote that 'the domain of temporal things is still populated with something non-present' (emphasis added). Whether or not it is obvious that the quantifier domain 'is still' populated by that which is no longer, and perhaps not yet, present, depends on which interpretation of the 'is' we are employing. That the 'is' is followed by 'still' suggests that Crisp intends interpretation (ii). If existential generalisation is permitted only for that which

\footnotetext{
7 The rejection of the tense version of the Barcan formula, here, need not be accompanied by the rejection of the tense version of the converse Barcan formula, viz. ' $\exists x F \varphi x \supset F \exists x \varphi x$ '. However, presentists would have cause here to be careful, for example, to discriminate the truth of the following two claims, ' $\exists x F \sim \varphi x$ ' and ' $\exists x \sim F \varphi x$ '. Consider the claim that 'For some $x$, it will be the case that ( $x$ does not exist)' that has the form of the former formula. This claim prima facie looks rather plausible. But given the acceptance of the reverse Barcan formula, it would entail that 'It will be the case that (there is some $x$ and $x$ does not exist)'. The presentist will want to reject this entailed claim, so they will need to either reject the tense version of the converse Barcan formula, or the antecedent claim that we remarked as having prima facie plausibility. Those presentists looking to preserve the tense version of the converse Barcan formula could, however, reject the claim that 'For some $x$, it will be the case that ( $x$ does not exist)', and complain that any plausibility that this assertion has is due to its confusion with the truth of the similar claim that 'For some $x$, it will not be the case that ( $x$ exists)', which has the form of the latter of the two formulas to be discriminated. This latter formula has none of the worrisome entailments for presentists. And likewise, the same applies mutatis mutandis for the past tense operator.
} 
is in this sense, then Meyer is right to protest that we are back with the triviality charge of P3.

If, however, no restriction on the validity of existential generalisation to names whose referents are present is made, the interpretation of presentism appears to be impaled on the other horn of the dilemma as a manifest falsehood. Meyer expounds this criticism, with no explicit reference to Crisp (2003, 2004a, b), in the following paragraph:

What is at issue [in the triviality objection], [the presentist] might claim, is whether names like "Caesar" have a referent. I seem to assume that the question has already been settled in his opponent's favor by using the existential generalization from JC ['Caesar crossed the Rubicon'] to "There is something that exists temporally." But suppose we follow this suggestion and permit existential generalizations only for names that presently have a referent. Then the notion of existence employed is really exists now (and not exists temporally), and we're back to the trivial ['Nothing exists now that is not present']. If we don't impose such a present referent condition then we do get ['Nothing exists temporally that is not present'], but we also get the above problems with JC. So the problem for the presentist arises independently of our views about reference. (2005, p. 101)

Now, Crisp will undoubtedly want to repel this accusation that the existential 'is' is not the triviality inducing tensed 'is'. That, though the quantifier's domain includes only present things, it is 'open' to non-present things. My inclination is that Crisp is right to appeal to this unrestricted (or at least relevantly restricted) quantifier to state presentism, like in Existence Simpliciter, but that his associating this with the detensed or tenseless 'is' [interpretations (i) and (iii)] is a mistake. After all, the detensed and tenseless 'is' are defined such they should include that which did or will exist. This aspect of these interpretations of 'is' prevents us making progress using them with respect to neutrality of our quantifiers. That is, rather than leaving open whether our quantifiers range only over that which is present, or over the non-present also, these interpretations analytically settle this dispute in favour of the more inclusive answer. All hope then rests on being able to make greater headway with the tensed interpretation of 'is', interpretation (ii). As we shall see in the next section, I think we can.

What Crisp's response rightly highlights is that the disputed set of statements that presentists reject and non-presentists tend to accept, are not just any past and future tensed statement, but specifically de re past and future tensed statements. This should not have been surprising, since presentism is typically intended as an ontological thesis: a thesis about what things exists. We need then an interpretation of the 'is' in Standard which we can use to sensibly reject certain seemingly true de re past and future tensed statements such as B.

\subsection{A tense refinement}

It is my contention that the triviality objection errs with its claim that a tensed interpretation of 'is' will necessarily yield a trivial characterisation of presentism. That is, 
I wish to challenge $\mathbf{P 3}$ from the triviality objection. This interpretation would render Standard with the following interpretation of 'is':

Standard Tense: Everything is (now) present.

This rendering of Standard seems the most natural in English. Indeed, I believe that there is in fact little ambiguity between different senses of 'is' along the temporal dimension [along interpretations (i)-(iv)] in English. ${ }^{8}$ Rather, the relevant distinction regarding the 'is' that should be made is between what there is at the now ${ }^{9}$ and what there is as of now. The former gives us the sense of restricting our interest (restricting the quantifier domain) to what is temporally located at the now. Whilst the latter has no such restriction on our interest (no restriction to the quantifier domain) to that which is now, but merely concerns the constitution of reality when it is now. When the quantifier appears within the scope of a past or future tense operator, as is customary in English, the now should be supplanted with then. ${ }^{10}$

It is not the sense of 'is' that changes; the 'is' is typically univocal along the temporal dimension. Instead, it is the typically suppressed cues, 'at the now' and 'as of now', that distinguish between the varying domain interests of our quantifying expressions. It is the former (domain-restricting) cue that yields a trivial interpretation of presentism. But the latter (non-domain restricting) cue results in an interpretation of Standard Tense which is neither trivial, since the domain is not restricted to the present moment, nor manifestly false (like the detensed and tenseless interpretations of 'is'), because it is not stipulated that the domain does or does not include that which existed or will exist. That is, if those things that existed or will exist exist as of now, they will not be excluded from the quantifier's domain. If they do notexist as of now, then they will be excluded from the quantifier's domain.

As an example, to demonstrate the distinction, consider the Growing-Block Thesis. According to this thesis, all past and present things, but not future things, exist. The sense in which these past things exist is not that they exist at the now. That would make the growing-block thesis manifestly false, since not all past things are present. Nor is it that they existed, since that would make its substantive claim a mere triviality. Rather, it is that those things that existed still exist as of now. Since, when it is now, not only do present things exist, but past things do also, or so growing-block theorists contend.

This distinction between the restricting and non-restricting connotations of is (now)' is something that even a deflationist about tense can endorse; though they will want to offer a less substantive understanding of 'now' than the tense realist does. This might be an indexical or token-reflexive sense of now. If one does not believe that

\footnotetext{
8 I do not wish to deny that our language does, or could be developed so that it does, include the use of the tenseless sense of 'is'. Indeed, I suspect that the tenseless sense of 'is' might be commonplace when it concerns the 'is' of generic implication, the kind of 'is' that I suspect is employed in mathematics.

9 If you do not like the phrase 'at the now', translate as 'at the present (moment(s))'.

10 Do not read anything deep into the change from "now" to "then" within the scope of tensed operators. This is merely an attempt to preserve some continuity with ordinary English, rather than deployment of a differently relativised quantifier. Both are relativised to what is present, it is just that, since what was or will be present is different from what is currently present, using "then" instead of "now" highlights that when the nested proposition is true the present is different.
} 
there is any change in what exists as of now, then the subordinate clause, as of now, will become redundant when expressing the unrestricted quantifier. But as common sense dictates, most people, though perhaps not most philosophers, think that 'when it (the present) is, is important to what there is'; that what exists as of now changes. So this way of understanding the tensed 'is' (interpretation (ii)) is neutral with respect to presentism and its main rivals.

We should want our logical vocabulary to be rich enough to capture the distinctions between the various metaphysical positions so that the debate can be adequately represented therein. Only given a neutral construction of the logical vocabulary can logic be of any help as an intellectual tool employed to help settle a debate. The privileged (fundamental) interpretation of the quantifier should therefore be reserved to express without restriction 'what there is as of now'. It is this sense of 'is', if any, that corresponds to what exists simpliciter; the missing interpretation delivering unrestricted quanitification (see Sect. 2.1). Whilst the interpretation of the quantifier as expressing 'what there is at the now' should be understood as derivative from the privileged quantifier, a mere restriction of its scope. To demarcate these two interpretations I will subscript the quantifiers with 'As' and 'At' respectively for the privileged and derivative interpretations. So we would formalise 'There is as of now a dinosaur' as ' $\exists$ As $\mathrm{x}(\mathrm{Dx})$ '. Likewise, we would formalise 'There is at the now a dinosaur' as ' $\exists$ At $\mathrm{x}(\mathrm{Dx})$ '. And whilst the latter is manifestly false, the former is anything but. This will allow us to clearly disambiguate how the quantifier should be interpreted in each context, as well as elucidate other important theoretical distinctions.

So we are now in a position to give a substantive statement of the presentist thesis that is not manifestly false, namely:

Standard Tense*: Everything is (as of now) present.

Clearly then, Standard Tense* is consistent with A1, and as such, the triviality objection is mistaken. Moreover, we can give an explanation of why many smart people have made this mistake. It is because they confused Standard Tense* with the subtly different:

Standard Tense@: Everything is (at the now) present.

What is correct about P3 is that Standard Tense@ is trivially true. What is incorrect about P3 is that Standard Tense ${ }^{*}$ is a substantive thesis. ${ }^{11}$ Unfortunately, Standard Tense does not disambiguate these two readings, and objectors have taken advantage of this by suggesting that Standard Tense@ is the only way to interpret Standard Tense.

\section{Change, variation, and relativisation}

In this section, we will explore some important theoretical distinctions that this new logical apparatus allows us to express, and elaborate how those distinctions help to

\footnotetext{
11 Interestingly, this trivial understanding of the presentist thesis casts doubt on the commonsensical status of presentism that several advocates (cf. Zimmerman 2007, Sect. 7) think recommend it. Plausibly, it is Standard Tense@, and not Standard Tense*, that common sense recommends.
} 
bring clarity to otherwise confused dialectics. At least since McTaggart (1908), there has been controversy over what counts as 'real' or 'genuine' change in the world. According to McTaggart, '...if there is to be change it must be change of what occurs in time (for the timeless never changes), I submit that only one alternative remains. Changes must happen to the events of such a nature that the occurrence of these changes does not hinder the events from being events, and the same events, both before and after the change.' (Ibid., p. 460). He submits to us that all that is permanent does not really change. This includes both what occurs at a time and the ordering of times. In his jargon, what he calls the 'B-series' of time- a series that orders times using only B-relations, earlier than, simultaneous with, and later than - does not vary across times. So although a poker may be hot one moment and cold another, this fact is unalterable for all time. Real change, if there be such, must be an alteration in that besides which we have just presumed fixed; according to McTaggart, real change involves the transience of A-determinations.

Infamously, McTaggart thought that the transience of A-determinations was incoherent, and as such, there could be no real change. Since he thought that time demanded real change, he concluded that time itself was unreal. ${ }^{12}$ Yet, our experiences appear to tell us otherwise. Though my experiences may be different at different times, and ordered with respect to each other, at least one of my experiences seems privileged. Namely, the experience I am having now. And which of my experiences, amongst the many spread across my entire lifespan, possesses this privilege seems to alter with time's vicissitudes, what we earlier described as time's apparent 'passage'.

Unsurprisingly, many, like McTaggart, have doubted whether things are as they appear to be with respect to temporal passage. My present concern is not with settling this debate, but rather about how to express what is at issue. Since, perhaps one of the biggest obstacles facing those who believed in real change in the world is how to express it. To understand the problem, let us look at how presentists, as those typically ranking amongst those who believe in real change, would express their belief in it. For them, this real change is often ontological change. That is, what things there are changes with time's flow, since for presentists, only present things exist, and if the presentness of things is transitory, then their existence will likewise be transitory.

\subsection{Change and variation}

Presentists will therefore want to express their commitment to real change, in, for example, the existence of humans, by stating that 'It is now the case that humans exist and it will be the case that no humans exist'. Formally, we can express this accordingly:

$$
\text { (1) } \mathbf{N}(\exists x(H x)) \& \mathbf{F}(\sim \exists x(H x))
$$

However, many who do not believe in real change in the existence of humans would nonetheless be happy to assert (1). They would claim that (1) is made true by there

\footnotetext{
12 McTaggart summarises these implications as follows: 'Without the A series then, there would be no change, and consequently the B series by itself is not sufficient for time, since time involves change.' (1908, p. 461).
} 
being humans simultaneous with the utterance, and no humans at a time later than the utterance. And indeed, those who do not, as well as those who do, believe in real change, could agree to the obtaining of these truth-conditions. This is because the quantifiers naturally read as being tensed (interpretation (ii)) due to their occurrence within the scope of the tensed operators. But then the truth-conditions of the first and second conjuncts of a token of (1) do not seem to conflict in the way that we would expect real change to. In particular, that which makes that token of (1) true could plausibly permanently obtain, regardless of when we assess the claim from. The worry is that, if presentists cannot use (1) to express real ontological change, then they simply will not be able to express it.

How can this be? The confusion arises from the same source that fuelled the triviality objection: the failure to disambiguate between the two readings of the tense 'is'. Once we have made the distinction between what there is as of now and what there is at the now, we can simply distinguish the two conflated claims that (1) obscures, only one of which is committed to the contentious real change. Using our subscripted quantifiers from the previous section, we can disambiguate (1) as follows:

$$
\begin{array}{r}
\left(1^{*}\right) \mathbf{N}\left(\exists_{\mathrm{At}} \mathrm{x}(\mathrm{Hx})\right) \& \mathbf{F}\left(\sim \exists_{\mathrm{At}} \mathrm{y}(\mathrm{Hy})\right) \\
\left(1^{* *}\right) \mathbf{N}\left(\exists_{\mathrm{As}} \mathrm{x}(\mathrm{Hx})\right) \& \mathbf{F}\left(\sim \exists_{\mathrm{As}} \mathrm{y}(\mathrm{Hy})\right)
\end{array}
$$

To reiterate, the quantifiers subscripted with 'As' quantify over what there is as of that now, whilst quantifiers subscripted with 'At' quantify over what there is at that now. So $\left(1^{*}\right)$ reads as, 'It is now the case that there is at the now a human, and it will be the case that there is not at then a human'. Whilst $\left(1^{* *}\right)$ reads as, 'It is now the case that there is as of now a human, and it will be the case that there is not as of then a human'. We shall say that statements like $\left(1^{*}\right)$ commit us merely to temporal variation, whilst claims like $\left(1^{* *}\right)$ also commit us to metaphysical change as well as temporal variation. By 'metaphysical change' I shall mean change in what exists, or the qualities of existents, as of now. Whilst, by 'temporal variation' I shall merely mean that, what exists, and what qualities existents possess, varies between what there is at each time. Though, metaphysical change entails temporal variation, the reverse entailment does not hold. My contention is that real change just is metaphysical change of some sort or other.

So, consider eternalism again, understood now as the metaphysical thesis that past, present, and future things exist as of now. $(1 *)$ is not something that eternalists and presentists need disagree about. After all, those humans existing at the now may or may not continue to exist as of a future now, but not at a future now. This would be an example of mere temporal variation. However, eternalists cannot, ${ }^{13}$ whilst presentists can, accept ( $1 * *)$. This would be an example of metaphysical change. All this thanks to our distinction between 'is (as of now)' and 'is (at the now)'.

It is worth emphasising here an oddity regarding those that accept metaphysical change who nonetheless attempt to characterise their view with a tenseless or detensed reading of the copula. That is the clear hopelessness of the task they attempt. For that which is tenseless or detensed is permanent, fixed, unchangeable, by definition. Yet

13 Assuming, contrary to the Shrinking-Tree Thesis (cf. McCall 1994), that all futures come to be present. 
metaphysical change presupposes that what there is or the way things are, is temporary, and that is just another way of saying that the italicised 'is' and 'are' are indeed tensed. You cannot escape a tensed reading of copulae if you believe in metaphysical change; metaphysical change necessarily denies us a complete, tenseless or detensed, description of reality. ${ }^{14}$

\subsection{Change and relativisation}

Besides the distinction between metaphysical change and mere temporal variation, there is an important distinction to be made between metaphysical change and temporal relativisation. Several theorists have seized upon the "as of" modification of what there is. Of particular relevance, some philosophers of time have employed the "as of" modification of what there is in their attempts to develop a coherent dynamic account of time (cf. Button 2006, 2007; Tooley 1997). ${ }^{15}$ But these former uses differ in some telling ways with my own. The most important difference is that, whilst the "as of" modification suggests a relativisation of what there is to whatever metaphysical index the modification takes, my usage only permits one temporal index in a time series: to the objectively present time. ${ }^{16}$ That is, I am not using the "as of" modification to relativise what there is, but merely as a way of capturing all that there is. It is through absolute change in what is objectively present that what is in the unrestricted quantificational domain changes. And this is what is meant by metaphysical change, and how to understand a truly dynamic account of time and reality.

This contrasts with Michael Tooley's understanding of a dynamic account of time outlined in the following passage:

...how can the totality of states of affairs be different at different times? The answer is that this will be possible only if, in the case of temporal facts or states of affairs, facts are, fundamentally, temporally relative, so that the basic notion is not that of states of affairs being actual simpliciter, but that of states of affairs existing, or being actual, as of a particular time. And given this temporally relative conception of facts, or states of affairs, there will presumably be nothing problematic about the idea that the totality of facts that are actual as of one time

\footnotetext{
14 I thank two anonymous referees for this journal for inviting me to elaborate here upon how my 'as of' terminology relates to similar uses in the literature.

15 An anonymous referee for this journal has pointed out to me that Button $(2006,2007)$ does not in fact make the mistake as characterising the position he there outlines as "dynamic". I agree that Button, much to his credit, seems to have been careful in avoiding any locutions suggesting that the position he described is dynamic, whereby the position itself is describe as 'no-futurism' rather than a 'growing-block theory'. Still, he does not explicitly deny that the position is dynamic, and it will be fruitful to see why it would be wrong to characterise it as such.

16 Though, if time were disunified, that there are multiple time series', then there would be multiple presents, each belonging to those distinct time series', for which my usage of "as of" permits what there is to be relative to. In this way can the presentist permit both disunified time-contrary to Arthur Prior's (1967b, pp. 198-199) contention — and branching time — contrary to Robin Poidevin (1996) early contention—without having to give up '...the usual presentist assumption that everything that exists is simultaneous' (Le Poidevin 2007, p. 166), as Le Poidevin contends that a presentist must.
} 
may be different from the totality of facts that are actual as of some other time. (1997, p. 14)

For Tooley, change consists in the permanent fact that what there is relative to one time is different to what there is relative to another. This usage of the "as of" modification of what there is relativises, in contrast to my own, can take more than the one privileged temporal index (the objective present). There are no privileged times on this temporal relativisation account of from what time reality is oriented. And these relativisations of what there is relative to (or "as of") a time each capture a different quantificational domain. On this account, change would merely constitute a shift in perspective to a different domain. As such, this is not metaphysical change, and consequently Tooley is not offering us a genuinely dynamic account of time here.

This links to another important difference between Tooley's account of the "as of" modification and my own. Tooley's unrestricted quantificational domain is not of what is temporally relative, but what there is simpliciter. And what there is simpliciter for Tooley includes absolutely all states of affairs, including all those belonging to some domain of what there is as of a time, as well as states of affairs that do not belong to any domain of what there is as of a time. So what there is as of a time on Tooley's account are merely restricted domains of what there is simpliciter. ${ }^{17}$ They are restricted in two ways: (i) they do not include states of affairs at times later than the time that the restricted quantification is indexed, and (ii) they do not include atemporal states of affairs. In contrast, my account of what there is as of present is not restricted in either of these ways. Indeed, it is not restricted at all, but rather corresponds to what there is simpliciter. Where Tooley disagrees with tensed theorists is in they believe, and Tooley does not believe, that what there is simpliciter changes. And it is because what there is as of a time all belong to what there is simpliciter for Tooley, that he must contend that those facts are tenseless, lest we arrive at McTaggart's $(1908,1927)$ conclusion that events are both past, present, and future, and not-past, not-present, and not-future, together.

It is at this point that Tim Button $(2006,2007)$ departs with Tooley. Button, like Tooley, thinks that growing-block theorists should adopt a temporal relativisation strategy of what there is as of a time. But he has different aims to Tooley. He suggests it as a way for growing-block theorists to avoid what Bourne (2002, 2006, Chap. 1) has called the Present Problem. Arthur Schopenhauer gave a nice outline of this kind of problem in the following passage:

Why precisely is he, the questioner, so lucky as to possess this precious, perishable, and only real present, while those hundreds of generations of men, even the heroes and sages of former times, have sunk into the night of the past, and have thus become nothing, while he, his insignificant ego, actually exists? Or,

\footnotetext{
17 Tooley does state that '...the concept of being actual as of a given time must be taken as primitive, and as incapable of being analysed.' (1997, p. 37). However, Tooley does not explain why actuality as of a time cannot be analysed in terms of a restriction of actuality simpliciter (either conceptually or metaphysically). And as far as I can tell, it should be analysed in that way if actuality simpliciter and actuality as of a time are to be related in the ways he wants them to be. But then I suspect that Tooley (1997) is not offering a genuinely metaphysical alternative to standard B-theory, or a version of the growing-block thesis proper, but merely a semantic alternative for how to understand tensed expressions.
} 
more briefly, although strangely: Why is this now, his now, precisely now, and was not long ago? Since he asks such strange questions, he regards his existence and his time as independent of each other, and the former as projected into the latter. He really assumes two nows, one belonging to the object and the other to the subject, and marvels at the happy accident of their coincidence. (1859, Bk. IV, Sect. 54, p. 279)

Schopenhauer carefully distinguishes here two senses of "now': "one belonging to the object and the other to the subject". This distinction maps onto the modern philosophical distinction between the token-reflexive and the metaphysical nows. The former 'now' is understood as a token-reflexive expression picking out whatever time(s) is (are) simultaneous with the tokening that contains it. The latter 'now', in contrast, picks out the metaphysically privileged time(s), irrespective of the time of tokening. Let us call these two 'now's, 'now $i$ ' and 'now $m$ ' respectively. The problem is then how a dynamic account of time positing non-present past or future existents can secure the happy coincidence between now $i$ and now $m$. If it cannot, then assuming that theory's truth, we could not know we are now $_{i}$ now $_{m} .{ }^{18}$

Button thinks that by treating reality as temporally relative, as of any now ${ }_{i}$, it will be the case that we are now $_{m}$. He seems to think that for there to be an objective now $_{m}$, reality must as of any time be tensed: 'Tense is plainly indispensable to this solution. So, with apologies to Tooley, no-futurists must believe that there are tensed facts.' (2006, p.133). And since reality is tensed, those tensed facts cannot appear together in a domain of what is real simpliciter, lest we get McTaggart's $(1908,1927)$ contradiction. Accordingly, he states that, "The no-futurist must therefore part company with Tooley, who claims "there can be a complete and consistent description of the world that is not a description from any particular temporal perspective' (1997, p. 16)." (Button 2007, p. 327). So, for Button, what there is as of a time captures unrestricted quantificational domains, "for the total reality of moments "differs' from moment to moment." (Ibid.). But since he is outlining a temporal relativism, there is a plurality of unrestricted domains. So unlike my ontological monist account of reality, Button is offering an ontological pluralist account of time (cf. McDaniel 2009a, b). ${ }^{19}$ That is, there is a different sense of what there is corresponding to each time, none of which has any more metaphysical privilege than any other. However, he never really provides any need for irreducible tense in these temporally relative realities (cf. Tallant 2011, Sect. 5), and it seems to me that Tooley is right to think that they are fundamentally tenseless. $^{20}$

\footnotetext{
18 This is not obviously such a bad result, since any belief that we are now now $_{m}$ would seemingly be underwritten by presentism. If presentism were false, then I see no reason why we ought to accept the platitude. However, the denial of this platitude undercuts many, though not all, of the motivations for believing in non-presentist dynamic accounts of time (cf. Bourne 2006, pp. 29-30).

19 In this way, Button is (explicitly) in agreement with Michael Dummett (1960), that there cannot be a complete description of reality. It is a version of Fine's $(2005 \mathrm{~b}, 2006)$ external relativist non-standard tense realisms.

${ }^{20}$ Button's justification appears to be the following: 'One cannot infer from the fact that no moment is [tenseless] special to the claim that no moment is [tensed] special. For no-futurists, the present moment is the last moment of time.' (2006, p. 133). Yet, this just confuses what it means for there to be irreducibly tensed facts. Tense is only needed where the facts undergo metaphysical change. In Button's model, the
} 
Button's conceptual confusion runs deeper though. As Tallant (2007) pointed out, this temporal relativisation strategy does not secure that what is now is now $_{m}$, it may well be past $_{m}$ as of a time. In this way Button fails to appreciate the distinction between what is real at a time from what is real as of a time. ${ }^{21}$ That is, what is presently (de dicto) the case need not be now $m$ (de re). Yet, Button complains that by introducing a primitive asymmetric "is real as of" relation, ${ }^{22}$ he avoids this unfavourable result, since "Sunday is not 'changed in moving from PRESENT to PAST' (or some such clumsy locution); Sunday as-of Tuesday is identical with Sunday as-of Sunday." (2007, p. 326). There are number of problems with this proposal. Firstly, whilst Sunday as-of Tuesday may be intrinsically indiscernible from Sunday as-of Sunday, it will not be extrinsically the same. Secondly, he lacks the resources to make this identity claim. For the two Sundays belong to distinct temporally relative domains, and since he has rejected Tooley's tenseless domain of what there is irrespective of time, there is no quantificational domain from which such cross-relative-domain comparisons can be made. And it is for this reason that Button must deny that the "is real-as-of" relation cannot be tensed (the temporally relative 'is') or tenseless (the atemporal 'is'), which we earlier (Sect. 2.1) described as nonsensical (see also Tallant 2011, p. 48, for similar problems relating to the 'is' in 'is earlier than').

This also means that Button fails to collapse (by identification) the two senses of the A-determinations (cf. Broad 1938, p. 278; Crisp 2003, Sect. 2.4.2; Tooley 1997, Sect. 10.3.2) that the growing-block thesis is necessarily committed too. That is, genuine growing-block theorists need to recognise the commitment of the growing-block thesis to two temporal levels: Time and Meta-Time. Time captures mere temporal variation within reality. The growing-block thesis is committed to No-Futurism about time: that all merely past and present, but not merely future, things exist. Meta-time captures changes to (or "relativisation of", in Button's case) the shape of time. The growing-block thesis is committed to Temporal Dynamism about meta-time: what is past, present, and future changes. These distinct temporal levels need not be dimensions, but they do reflect the different senses of the A-determinations required to express the growing-block thesis. ${ }^{23}$

The reason why what is now $i$ need not match up with what is now $_{m}$ for the nonpresentist is that the at a time modification is merely a domain restriction of what there

\footnotetext{
Footnote 20 continued

facts about what is real relative to a time are unchanging. And the mere adding of metaphysically privileging A-determinations_-pastness, and presentness - that fundamentally do not change, but instead are simply relativised to times, does not make the description tensed, even though as of each time, one time may be metaphysically privileged.

21 Tooley (1997) also seems careless at points, switching to the at a time modification when outlining the corresponding temporally relative account of truth, whilst preserving the as of a time modification for his temporally relative account of reality.

22 This relation ought to be non-symmetric, since simultaneous things will presumably be real as of each other.

23 Button's (2007) semantics mirroring Lowe (1998a, b, Chap. 4, Sect. 2) tensed token-reflexive semantics equivocates between these two senses of the A-determinations. Though, Button's earlier semantics actually seems closer to that of Priest (1986) and Smith (1993, pp. 102-105), with remarks like 'Me-on-Monday was right when it mattered, which is surely all that is required.' (Button 2006, p. 133). But Philip Percival (2002, pp. 104-105) has clearly explained why this alternative non-presentist tense semantics is unsatisfactory.
} 
is as of a time. But, if as of a time there is a plurality of times, that restriction need not be a restriction to the time that is now $m$. So what there is at the time that is now need not be now $m$. What we have seen here is that previous uses of the "as of" modification in the literature on time have differed in important ways from my own, and failed to clearly distinguishes it from the "at a" modification. And it is crucial when offering a genuinely dynamic account of time, that we do not confuse metaphysical change with temporal relativisation, for the latter is no more real change than mere temporal variation.

\section{Temporal versus existential priority}

Underlying these issues resides an important difference between eternalist and presentist conceptions of the relationship between time and existence. This is a difference in priority. Eternalists think of time as posterior to existence, whereby time has an ontology. That ontology consists of the times and whatever temporal relations they may bear to one another. A comprehensive survey of all that exists will reveal all of time, a complete description. In contrast, presentists think that it is existence that is posterior to time; that existence is subject to time's vicissitudes. Time has no ontology, but rather concerns the behaviour of ontology. Time just is the metaphysical change in which things exist and what they are like, and this is not something that can be found by any inspection of that which exists, no matter how thorough. Hence, St. Augustine's comment that '...we cannot truly say that time exists except in the sense that it tends towards non-existence.' (c.397-398, Bk. XI, Sect. 17, p. 231).

I outline these differing conceptions of the relationship between time and existence, here, in order to make an observation about the triviality objection. The objection is set up in a way that presupposes that existence is subject to time. It is assumed that there is no notion of existence that is not intimately bound up with time. The objector permits us the tensed notion of 'is', the 'is (at the now)'. We are then granted use of the 'is' under an 'omnitemporal' interpretation to mean 'was, is (at the now), or will be', with maybe an extra disjunct for the atemporal, as if we were being granted some alternative conceptual scheme. But this is no concession at all, since we can already say everything with the tensed 'is', 'was', and 'will be', that we can say with the omnitemporal 'is'. Yet, if 'is' just means 'is (at the now)', then, in some weak sense, presentists have already won. But they are not permitted to make the substantive claim they want to make; they are to settle for triviality.

Eternalists want to claim that past and future times exist. Times are just further existents, and so 'what there is', in the unrestricted sense, cannot be taken to mean 'what there is at the now' by eternalists, or else they will have all times at once in the now. Nor do they intend to make the trivial claim that all times were, are, or will be. When they speak of what there is, the matter of when it (the present) is, is just not relevant, since what there is does not really change. The question of which is prior, time or existence, is one of the central points of contention between presentist and eternalist. To deny eternalists their way of speaking without argument is merely to beg the question against them. So the triviality objection offends both presentism and eternalism. Indeed, the objection seeks to deflate the debate by denying any useful 
conception of 'is' upon which to frame it. I hope to have shown, among other things, that a perfectly comprehensible neutral conception of 'is' can be had upon which to found the presentist-eternalist dispute.

\section{Ontic and factive presentism}

When outlining our accounts of the A-determinations and the resultant interpretations of the presentist thesis, we will need to be careful not to confuse two closely related, yet distinct views: the views that Fine (2005b, pp. 298-300), unhelpfully, labels 'ontic' and 'factive' presentism. Factive presentism is more commonly known under the guise of 'tense realism'. In Fine's own words, it '... is the view that reality is tensed; reality comprises tensed facts (and perhaps tenseless facts as well). Tense-theoretic realism is, in its own way, a form of presentism; for, in so far as reality comprises tensed facts, it must be oriented towards the present. We might therefore call it factive as opposed to ontic presentism.' (Ibid., p. 299). That is, it is a view about the nature of facts. In particular, that there are irreducibly tensed facts. By 'fact', I understand Fine as meaning whatever it is about the world that makes propositions true.

Ontic presentism, however, is the thesis which has so far been our focus, summarised above as the presentist thesis that 'all and only present things exist'. It does not directly concern facts, but rather is a thesis concerning what the facts are about or involve. In particular, it is the thesis that whatever the facts are about, if they are about any existents at all, they are about present existents. Fine construes his distinction thus: 'Ontic presentism is an ontological position; it is a view about what there is. Factive presentism, on the other hand, is a metaphysical rather than an ontological position; it is view about how things are, quite apart from what there is.' (Ibid.).

Importantly, factive presentism does not entail ontic presentism. That is, factive presentism is permissive about non-present existence; it allows merely past or future existents. In fact, Fine claims to find greater plausibility in factive presentism without ontic presentism. Yet, ontic presentists at least ought to be factive presentists, even if there is no strict entailment from the former to the latter either. As Fine notes, 'Ontic presentism, by contrast, does not really make sense except in the context of factive presentism. There is no strict implication from one to the other but, given that all the facts are tenseless, it makes no sense to restrict the ontology to presently existing things. Thus any argument against factive presentism is, eo ipso, an argument against ontic presentism.' (Ibid., p. 300). Fine presumably denies strict implication because it seems possible for ontic presentists to both, deny that there is any metaphysical change, and accept a reductive tenseless understanding of presentness. ${ }^{24}$ Such a combination of views would be extremely unattractive.

\subsection{The extended presentist thesis}

Aside from our caution not to confuse ontic with factive presentism, another reason for making this distinction here is to highlight the strictly ontological nature of the

\footnotetext{
24 For a version of ontic presentism that might meet these constraints, see Dainton's (2001, Sect. 6.8) Solipsistic Presentism.
} 
presentist thesis as so far construed. Many will undoubtedly complain that this way of construing the thesis does not do justice to what they have meant by presentism. They would have us extend the presentist thesis to include not only a statement about what there is, but also the way they are. So, for example, when Trenton Merricks characterises presentism, he goes beyond the mere ontological claim: 'Presentism is the doctrine that the present time is ontologically privileged. According to the presentist, all that exists, exists at the present time; and an object has only those properties it exemplifies at the present time.' (1995, p. 523, the second emphasis is mine). That is, not only is what things there are restricted, but the exemplification of properties is similarly restricted so that only present property exemplifications obtain.

Let us call this extension of the presentist thesis the 'extended presentist thesis'. We shall prefer to formulate the extension accordingly, so that it does not reference times:

Extended Presentist Thesis: All and only present things exist. And all and only present property exemplifications obtain. ${ }^{25}$

Like ontic presentism, factive presentism does not entail the Extended Presentist Thesis. It is natural, though not compulsory, ${ }^{26}$ for ontic presentists to extend their view in this way, since without this additional claim about property exemplifications, it is unclear how presentism helps endurantist theories of persistence ${ }^{27}$ in the way that Zimmerman (2005) et al. intend it to.

Typically endurantists are forced to relativise, in some preferred way, property instances of enduring objects to times in order to avoid the otherwise incompatible property instances instantiated by an object at distinct times from conflicting with each other. ${ }^{28}$ But ontic presentism is meant to be able to remove the conflict without the relativisation of property exemplifications, in some preferred way, to times. It does this by ensuring that, when, in an enduring object, a property instance of a future time succeeds its incompatible property instance of this time, that future property instance does not yet obtain (as of now). And when it eventually does, the property instance of this time will have ceased to obtain (as of then). Hence, the two incompatible properties will never be exemplified together in the same object. However, this will only be ensured by the Extended Presentist Thesis. Ontic presentism alone does not get us this favourable result.

Ontic presentism fails to deliver this result on its own is partly because it permits present existents, if they endure, to also be past or future existents as of now. If they did so, we might expect past or future property exemplifications of that past or future

\footnotetext{
25 I am using 'property' broadly here to include relations, and in a way that is neutral on the metaphysics of properties.

26 In particular, ontic presentists adopting a nominalist or universals account of properties could consistently reject Extended Presentist Thesis.

27 Roughly, Endurantism is the thesis that things persist by being wholly present at distinct times.

28 This so called 'problem of temporary intrinsics' was delineated by David Lewis thus: 'Persisting things change their intrinsic properties. For instance shape: when I sit, I have a bent shape; when I stand, I have a straightened shape. Both shapes are temporary intrinsic properties; I have them only some of the time. How is such change possible?' (1986, pp. 203-204).
} 
existent to likewise obtain (as of now) in the past or future. That is, ontic presentism does not rule out that present existents are (as of now) multiply-located at past and/or future moments, just as they are in certain eternalist metaphysics (cf. Mellor 1998).

Additionally, the Extended Presentist Thesis would rule out Frivolous Presentism. Frivolous presentists allow for property exemplifications by things at times when they do not exist (as of then). ${ }^{29}$ Though, most presentists welcome the commitment to Serious Presentism, the denial of frivolous presentism, ${ }^{30}$ there are others who are inclined towards frivolous presentism (cf. Hinchliff 1988, 2010). The latter kind of presentist would accept ontic presentism whilst rejecting Extended Presentist Thesis.

\subsection{De Dicto and De Re Tensism}

When considering Crisp (2004a,b) response to the triviality objection, I applauded him for noting that (ontic) presentists are not especially concerned with challenging de dicto tensed claims, only de re tensed claims. In particular, they are concerned to challenge whether there are (as of now) existents such that it is not now the case that they exist. That is, whether there are (as of now) existents that are non-present. We can capture the thought formally by stating that ontic presentists must deny all claims that entail the following:

$$
\text { (2) } \exists_{\mathrm{As}} \mathrm{x} \sim \mathbf{N}(\mathrm{x}=\mathrm{x})
$$

So, consider our earlier examples of de dicto and de re tensed claims:

A De Dicto: It was the case that (there is (as of now) an $x$, such that, $x$ is the Roman Empire).

B De Re: There is (as of now) an $x$, such that, it was the case that ( $x$ is the Roman Empire).

Given that the Roman Empire is no longer present, B De $\boldsymbol{R} \boldsymbol{e}$ entails (2), but A $\boldsymbol{D} \boldsymbol{e}$ Dicto, on the other hand, does not entail (2), since we rejected past and future tensed versions of the Barcan Formula, which includes:

Past Barcan Formula: $\mathbf{P} \exists x \varphi x \rightarrow \exists x \mathbf{P} \varphi x$

\footnotetext{
29 An anonymous referee for this journal asked "isn't it true (now) of The Roman Empire that it (was) vast? Is that a property exemplification by a thing at a time when the thing does not exist (as of then)?" In response, I would say first that its 'being true (now) of The Roman Empire that it (was) vast' is a predication, and not a property exemplification. If the truth of that predication is grounded in a property exemplification, then there may be a question of when the property exemplification takes place. It may be grounded in a present exemplification of a past-tensed (or past-directed) property or by a past exemplification of a present-tensed (or present-directed) property. By stating that 'Frivolous presentists allow for property exemplifications by things at times when they do not exist (as of then)', I am conveying that the frivolous presentist allows the truth of this predication to be grounded in the latter kind of way: by a past exemplification of a present-tensed (or present-directed) property.

30 See, for example, Brogaard (2006, p. 195), Crisp (2005, p. 7), Davidson (2003), Markosian (2004, p. 53), and Torrengo (2006, p. 117).
} 
That is, A De Dicto does not tell us whether the constituent of the fact that it expresses did exist (as of now) in fact presently exists (as of now). And since the existence (as of now) of that thing is left open, it does not conflict with (2). However, B $\boldsymbol{D} \boldsymbol{e} \boldsymbol{R} \boldsymbol{e}$ just is the assertion that that thing does (presently) exist (as of now), and consequently, if the existent were not also present, B De $\boldsymbol{R} \boldsymbol{e}$ would entail (2).

Those endorsing Extended Presentist Thesis will be similarly unconcerned with challenging de dicto tensed claims like A De Dicto. Their dispute, too, will be restricted purely to challenging de re tensed claims. But whereas ontic presentism specifically challenges the ontological aspects of such de re tensed claims, as (2) indicates, those endorsing Extended Presentist Thesis will seek also to challenge more broadly metaphysical aspects of de re tensed claims in addition to the ontological aspects. That is, they will want to deny that there are (as of now) any non-present property exemplifications, as well as rejecting (2). We can again capture the thought formally by stating that those endorsing Extended Presentist Thesis must reject all claims entailing the following:

\section{(3) $\exists_{\mathrm{As}} \mathrm{x}(\Phi \mathrm{X} \& \sim \mathbf{N}(\Phi \mathrm{x}))$}

Unlike ontic presentism or Extended Presentist Thesis, factive presentism does not concern itself with making de re tense claims. It is a thesis about the nature and structure of facts, not their constituents. That is, it concerns itself with de dicto tense claims, and in particular, the tense aspects of those factual claims. Though, the focus of factive presentism is not to challenge the truth of de dicto tense claims, as ontic presentism or Extended Presentist Thesis challenges the truth of de re tense claims, but rather whether true de dicto tense claims faithfully represent reality as irreducibly tensed. As Fine explains, the factive presentist's '...interest is in the tense or aspect of the statement rather than with its specific ontological or ideological content; we simply wish to know whether the tense or aspect of the statement might be an impediment to its faithfully representing the facts.' (2005b, p. 268).

It seems to me, then, that Fine's characterisation of the distinct interests of factive and ontic presentism as metaphysical and ontological respectively, does not best capture their difference in focus. After all, Extended Presentist Thesis is a broadly metaphysical thesis, yet, like ontic presentism, it does not tread on the toes of factive presentist concerns. Instead, the distinct interests are best represented simply as a concern with de dicto tense claims, in the case of factive presentism, or a concern with de re tense claims, in the case of ontic presentism and Extended Presentist Thesis.

\subsection{Strong factive presentism}

Another inadequacy about Fine's terminology is that a more fitting thesis for the title 'factive presentism' would be the thesis that all facts are present facts. It can be captured nicely by the wide scope applicability salva veritate of the present tense operator. For any fact, a present tensed operator can be prefixed to the expression of that fact without altering its truth-value. Or, more succinctly, the thesis that the following 
entailment holds: $\ulcorner\varphi \vdash \mathbf{N}(\varphi)\urcorner$. We shall call this thesis Strong Factive Presentism. ${ }^{31}$ This would parallel one way of construing the Extended Presentist Thesis. That is, if we construed it as the narrow scope applicability salva veritate of the present tense operator to all that which appears after the quantifier. So the following entailment would hold: $\left\ulcorner\exists_{\mathrm{As}} \mathrm{x}(\Phi \mathrm{x}) \vdash \exists_{\mathrm{As}} \mathrm{x} \mathbf{N}(\Phi \mathrm{x})\right\urcorner$. Strong factive presentism permits only present facts, whilst factive presentism as construed by Fine is inclusive of past and future facts. Indeed, it is because of this overabundance of facts that he needs to either relativise truth or fragment reality to avoid their conflicting with one another. ${ }^{32}$

Finally, by endorsing the tense reading of the 'is' above, some might think that I have already committed myself to strong factive presentism. However, this is a mistake, since factive presentism requires not just that there be tensed facts, but that those facts are irreducibly tensed. If the implicit 'now' in the tensed reading of the copula is given a tenseless reading, such as is proposed by token-reflexive semantics (cf. Mellor 1981, Chap. 2), then factive presentism may yet be false. In other words, the tensed readings of 'is' need not be irreducibly tensed; they may well be tenseless. What makes the 'is' irreducibly tensed is metaphysical change. Metaphysical change denies us a complete, fixed, once and for all, description of reality. That is, given metaphysical change, when we describe how reality is, the best we can do is state how reality is as of this moment, and not for all time, since how reality $i$ as of any moment itself changes with temporal vicissitudes. ${ }^{33}$

We can reasonably assume, then, that whether the tensed 'is' is irreducibly tensed or not will be determined by extrinsic factors: whether or not metaphysical change occurs. This makes it plausible to suppose that the view that the logical joint(s) that the 'is' helps represent, especially our quantifiers, will be intrinsically the same whether or not metaphysical change occurs. These reasonable assumptions will maintain the virtuous neutrality of those logical joints between eternalists and ontic presentists.

Finally, it should now be clear why the proposals by Merricks and Sider from Sect. 2.1, of reducing the debate between presentists and non-presentists to a dispute about which interpretation of the quantifier is joint-carving, will not do even when we add our disambiguated interpretations of the tensed 'is' into the mix. For, firstly, both presentists and non-presentists alike can accept the additional 'is (as of now)' interpretation. But also, and crucially, whether or not the quantifier is tensed turns on the redundancy of the de dicto readings of the present tensed operator. That is, it

\footnotetext{
31 This is not quite the same as saying that the present tense operator is 'redundant', as Arthur Prior (1967a) contends, since we need not accept the reverse entailment, $\ulcorner\mathbf{N}(\varphi) \vdash \varphi\urcorner$.

32 That is, if factive presentism permits past and future tensed facts as well as present tensed facts, it faces a version of McTaggart (1908, 1927) A-series paradox. As Mellor rightly notes, '...facts are no better at being at once both and not both past and present, present and future, and so on than events are' (1981, p. 95).

33 Note, none of the positions described by Fine (2005b, 2006), including both his standard version, and non-standard versions_external relativism and fragmentalism —of tense realism involve metaphysical change. It is therefore hard to see what justification can be given for contending that the tense aspects of reality are genuinely irreducible to the tenseless aspects on his positions. That is, Fine seems to squeeze out the tense from his 'tense realisms' by finding ways to give a complete description of reality, whether that be by fixing the A-determinations (as in his standard tense realism), temporally relativising aspects of that description (as in external relativism), or compartmentalising aspects of that description into fragments (as in fragmentalism).
} 
concerns whether or not strong factive presentism is true. But ontic presentists are not primarily making a claim about the fundamentality of presently existing, but rather the de re claim about whether those existents are presently such-and-such. They have both subtly conflated the issue in this way.

\section{Conclusion}

We have now established what should be held fixed in our interpretation of the presentist thesis in order to make it substantive and interesting. Namely, we have fixed our understanding of 'is' and thereby the quantifier expressions associated with it. This was precisified in Standard Tense*. And we have narrowed our focus of just what this way of understanding the thesis involves, as well as supplying the conceptual resources necessary to distinguish between real change from mere variation. However, the project of specifying a presentist theory is far from complete; it is a job half-done. This backbone of the presentist thesis is in need of supplementation with a worked out account of the A-determinations themselves. Especially since we have tied our understanding of 'is' and existence to presentness, and a tensed interpretation of those concepts.

Scarce work has been done to elaborate this central component of the presentist thesis, to state exactly what is meant by pastness, presentness, and futurity, despite increasing expressions of dissatisfaction (cf. Deasy 2014, Sect. 3.3; Rundle 2009, p. 90; Williamson 2013, p. 24). However, like Sider (2006, p. 76, fn. 2), space forces me to sidestep this issue here. Instead, I emphasise the limitations of this paper, highlighting where more work is required to develop thesis into theory, rather than leave my reader with the false impression that the work done here in any way settles our understanding of presentism. And encourage others to address the complementary elucidatory work with respect to the A-determinations. By improving our understanding of a thesis we thereby reduce confusion in its assessment.

Acknowledgements Thanks to Robin Le Poidevin and Jason Turner for their feedback on early drafts of this work. Thanks also to two anonymous reviewers for this journal for their helpful feedback and encouragement.

Open Access This article is distributed under the terms of the Creative Commons Attribution 4.0 International License (http://creativecommons.org/licenses/by/4.0/), which permits unrestricted use, distribution, and reproduction in any medium, provided you give appropriate credit to the original author(s) and the source, provide a link to the Creative Commons license, and indicate if changes were made.

\section{References}

Bergmann, M. (1999). (Serious) actualism and (serious) presentism. Noûs, 33(1), 118-132.

Bourne, C. (2002). When am I? A tense time for some tense theorists. Australasian Journal of Philosophy, $80(3), 359-371$.

Bourne, C. (2006). A future for presentism. Oxford: Oxford University Press.

Broad, C. D. (1938). Examination of McTaggart's philosophy. Cambridge: Cambridge University Press.

Brogaard, B. (2006). Tensed relations. Analysis, 66(3), 194-202.

Button, T. (2006). There's no time like the present. Analysis, 66(2), 130-135.

Button, T. (2007). Every now and then, no-futurism faces no skeptical problems. Analysis, 67(4), 325-332. 
Campbell, J. K., O’Rourke, M., \& Silverstein, H. S. (2010). Time and identity. Cambridge, MA: The MIT Press.

Chalmers, D. J., Manley, D., \& Wasserman, R. (2009). Metametaphysics: New essays on the foundations of ontology. Oxford: Oxford University Press.

Ciuni, R., Miller, K., \& Torrengo, G. (2013). New papers on the present: Focus on presentism. Munich: Philosophia Verlag.

Crisp, T. M. (2003). Presentism. In M. J. Loux \& D. W. Zimmerman (Eds.), The Oxford handbook of metaphysics (pp. 211-245). Oxford: Oxford University Press.

Crisp, T. M. (2004a). On presentism and triviality. In D. W. Zimmerman (Ed.), Oxford studies in metaphysics (Vol. 1, pp. 15-20). Oxford: Oxford University Press.

Crisp, T. M. (2004b). Reply to Ludlow. In D. W. Zimmerman (Ed.), Oxford studies in metaphysics (Vol. 1, pp. 37-46). Oxford: Oxford University Press.

Crisp, T. M. (2005). Presentsim and 'cross-time' relations. American Philosophical Quarterly, 42, 5-17.

Dainton, B. (2001). Time and space (1st ed.). Chesham: Acumen.

Davidson, M. (2003). Presentism and the non-present. Philosophical Studies, 113(1), 77-92.

Deasy, D. (2014). Permanents: In defence of the moving spotlight theory. Doctoral Thesis, St. Hilda's College, University of Oxford.

Dieks, D. (2006). The ontology of spacetime. Oxford: Elsevier.

Dorato, M. (2006). The irrelevance of the presentist/eternalist debate for the ontology of Minkowski spacetime. In D. Dieks (Ed.), The ontology of spacetime (pp. 93-109). Oxford: Elsevier.

Dummett, M. (1960). A defense of McTaggart's proof of the unreality of time. The Philosophical Review, 69(4), 497-504.

Fine, K. (2005). Tense and reality. In K. Fine (Ed.), Modality and tense (pp. 261-320). Oxford: Clarendon.

Fine, K. (2006). The reality of tense. Synthese, 150, 399-414.

Gallois, A. (1998). Occasions of identity: The study in the metaphysics of persistence, change, and sameness. Oxford: Oxford University Press.

Haslanger, S., \& Kurtz, R. M. (2006). Persistence: Contemporary readings. Cambridge, MA: The MIT Press.

Hestevold, H. S., \& Carter, W. R. (2002). On presentism, endurance, and change. Canadian Journal of Philosophy, 32(4), 491-510.

Hinchliff, M. (1988). A defense of presentism. Doctoral Thesis, Princeton University.

Hinchliff, M. (2010). The identity of the past. In J. K. Campbell, M. O'Rourke, \& H. S. Silverstein (Eds.), Time and identity (pp. 95-110). Cambridge, MA: The MIT Press.

Le Poidevin, R. D. (1996). Time, tense and topology. Philosophical Quarterly, 46(185), 467-481.

Le Poidevin, R. D. (1998). Questions of time and tense. Oxford: Clarendon Press.

Le Poidevin, R. D. (2007). The images of time: An essay on temporal representation. Oxford: Oxford University Press.

Lewis, D. K. (1986). On the plurality of worlds. Oxford: Basil Blackwell.

Lombard, L. B. (1999). On the alleged incompatibility of presentism and temporal parts. Philosophia, 27, 253-260.

Lombard, L. B. (2010). Time for a change: A polemic against the presentism-eternalism debate. In J. K. Campbell, M. O’Rourke, \& H. S. Silverstein (Eds.), Time and identity (pp. 49-77). Cambridge, MA: The MIT Press.

Loux, M. J., \& Zimmerman, D. W. (2003). The Oxford handbook of metaphysics. Oxford: Oxford University Press.

Lowe, E. J. (1998a). Tense and persistence. In R. D. Le Poidevin (Ed.), Questions of time and tense (pp. 43-59). Oxford: Clarendon Press.

Lowe, E. J. (1998b). The possibility of metaphysics: Substance, identity, and time. Oxford: Clarendon Press. Magalhães, E., \& Oaklander, L. N. (2010). Presentism: Essential readings. Lanham, MD: Lexington Books. Markosian, N. (2004). A defense of presentism. In D. W. Zimmerman (Ed.), Oxford studies in metaphysics (Vol. 1, pp. 47-82). Oxford: Oxford University Press.

McCall, S. (1994). A model of the universe. Oxford: Oxford University Press.

McDaniel, K. (2009a). Ways of being. In D. J. Chalmers, D. Manley, \& R. Wasserman (Eds.), Metametaphysics: New Essays on the foundations of ontology (pp. 290-319). Oxford: Oxford University Press.

McDaniel, K. (2009b). Ways of being and time. Available from: http://krmcdani.mysite.syr.edu/wobt.pdf.

McTaggart, J. M. E. (1908). The unreality of time. Mind, 18, 457-484.

McTaggart, J. M. E. (1927). The nature of existence (Vol. 2). Cambridge: Cambridge University Press. 
Mellor, D. H. (1981). Real time. Cambridge: Cambridge University Press.

Mellor, D. H. (1998). Real time II. London: Routledge.

Merricks, T. (1995). On the incompatibility of enduring and perduring entities. Mind, 104(415), 523-531.

Merricks, T. (2007). Truth and ontology. Oxford: Oxford University Press.

Meyer, U. (2005). The presentist's dilemma. In E. Magalhães \& L. N. Oaklander (Eds.), Presentism: Essential readings (pp. 99-108). Lanham, MD: Lexington Books.

Meyer, U. (2013). The triviality of presentism. In R. Ciuni, K. Miller, \& G. Torrengo (Eds.), New papers on the present: Focus on presentism (pp. 67-88). Munich: Philosophia Verlag.

Percival, P. (2002). A presentist's refutation of Mellor's McTaggart. In C. Callender (Ed.), Time, reality and experience (pp. 91-118). Cambridge: Cambridge University Press.

Priest, G. (1986). Tense and truth conditions. Analysis, 46, 162-167.

Prior, A. N. (1957). Time and modality: Being the John Locke lectures for 1955-1956 delivered in the University of Oxford. Oxford: Clarendon Press.

Prior, A. N. (1967a). On spurious egocentricity. In P. Hasle, P. Øhrstrøm, T. Braüner, \& J. Copeland (Eds.), Papers on time and tense (2nd ed., pp. 27-37). Oxford: Oxford University Press.

Prior, A. N. (1967b). Past, present, and future. Oxford: Oxford University Press.

Prior, A. N. (1968). Quasi-propositions and quasi-individuals. In P. Hasle, P. Øhrstrøm, T. Braüner, \& J. Copeland (Eds.), Papers on time and tense (2nd ed., pp. 213-221). Oxford: Oxford University Press.

Rescher, N. (1966). On the logic of chronological propositions. Mind, 75(297), 75-96.

Rundle, B. (2009). Time, space, and metaphysics. Oxford: Oxford University Press.

Savitt, S. F. (2006). Presentism and eternalism in perspective. In D. Dieks (Ed.), The ontology of spacetime (pp. 111-127). Oxford: Elsevier.

Schopenhauer, A. (1859). The world as will and representation (Vol. 1) ( E. F. J. Payne (1969), Trans.). New York: Dover Publications, Inc.

Sider, T. (2006). Quantifiers and temporal ontology. Mind, 115(457), 75-97.

Sider, T., Hawthorne, J., \& Zimmerman, D. W. (2007). Contemporary debates in metaphysics. Malden, MA: Blackwell.

Smith, Q. (1993). Language and time. New York: Oxford University Press.

Tallant, J. (2007). There have been, are (now), and will be lots of times like the present in the hybrid view of time. Analysis, 67(1), 83-86.

Tallant, J. C. (2011). There's no future in no-futurism. Erkenntnis, 74(1), 37-52.

Tooley, M. (1997). Time, tense and causation. Oxford: Oxford University Press.

Torrengo, G. (2006). Tenseless cross-temporal relations. Metaphysica, 7(2), 117-129.

Williamson, T. (2013). Modal logic as metaphysics. Oxford: Oxford University Press.

Zimmerman, D. W. (2004). Oxford studies in metaphysics (Vol. 1). Oxford: Oxford University Press.

Zimmerman, D. W. (2005). Temporary intrinsic and presentism, with postscript. In S. Haslanger and R. M. Kurtz (2006) (Eds.), Persistence: Contemporary Readings. Cambridge, Massachusetts: The MIT Press, (pp. 393-404).

Zimmerman, D. W. (2007). The privileged present: Defending an 'A-theory' of time. In T. Sider, J. Hawthorne, \& D. W. Zimmerman (Eds.), Contemporary debates in metaphysics (pp. 211-225). Malden, MA: Blackwell. 